\title{
Incidence of ventricular arrhythmias in first year after myocardial infarction ${ }^{1}$
}

\author{
J. FEDERMAN, J. A. WHITFORD, S. T. ANDERSON, AND A. PITT \\ From the Cardiovascular Diagnostic Service, Alfred Hospital, Melbourne, Australia
}

SUMMARY The incidence of ventricular arrhythmias in the first year after acute myocardial infarction was studied prospectively using 24-hour Holter electrocardiogram tape monitoring. Of 108 patients who entered the trial, 74 completed the 12 months of study. Patients were initially studied at 2 weeks after infarction then at 3-monthly intervals. Ventricular premature beats were observed in 80 per cent of studies, with these arrhythmias occurring in 57 per cent of the total hours studied. 'Significant' ventricular arrhythmias defined as ventricular premature beats greater than 1 in 10 beats, multifocal ventricular premature beats, bigeminy or trigeminy, salvos ( 2 or 3 consecutive ventricular premature beats), $R$ on $T$, or ventricular tachycardia (4 or more ventricular premature beats), occurred in 54 per cent of studies, with these arrhythmias occurring in 40 per cent of the total hours studied. The incidence of ventricular arrhythmias remained fairly constant for each 3-month period while the percentage of total studied hours for which ventricular arrhythmias occurred was significantly higher after the entry study at 2 weeks.

The incidence of ventricular arrhythmias was significantly higher in patients with inferior or posterior infarction after the entry study compared with those with anterior infarction $(P<0.005)$. Patients who had cardiac failure in the coronary care unit or a peak serum aspartate aminotransferase $>200 \mathrm{IU} / 1$ had a higher long-term incidence of ventricular arrhythmias $(P<0.01)$.

Four deaths occurred during the study. In all cases ventricular premature beats were observed on at least 1 period of study, with significant ventricular premature beats in 2 of the 3 patients who died suddenly.

A control group of 21 normal subjects had a random 24-hour Holter study and were found to have a significantly lower incidence of ventricular arrhythmias when compared with the post-infarction group. Ventricular premature beats were observed in 48 per cent of cases $(P<0.005)$ for 28 per cent of the total hours studied $(P<0.025)$ and significant ventricular arrhythmias in 19 per cent of cases $(P<0.005)$ for 35 per cent of the total hours studied.

The standard electrocardiogram proved to be a poor indicator of the true incidence of ventricular premature beats found on 24-hour Holter monitoring, with 75 per cent of patients having ventricular arrhythmias and 43 per cent showing 'significant' ventricular arrhythmias when all standard electrocardiograms showed no ventricular premature beats.

In patients with coronary artery disease 60 per cent of the deaths are sudden (Kuller, 1966). The major mechanism of death is thought to be ventricular fibrillation associated with ischaemia (Lown and Wolf, 1971; Schaffer and Cobb, 1975), since most findings at necropsy show evidence of

${ }^{1}$ Work sponsored in part by a grant from The National Heart Foundation of Australia.

Received for publication 6 January 1978 significant coronary artery disease without evidence of recent infarction (Schwartz and Walsh, 1971; Schaffer and Cobb, 1975). The magnitude of this problem has led to repeated attempts to define factors that might predict those patients at greatest risk, so that the prophylactic use of long-term antiarrhythmic agents could be considered. The presence of ventricular premature beats in patients with coronary artery disease appears to be one such factor and studies by Chiang et al. (1969), Hinkle et al. (1969), Coronary Drug Project Research Group 
(1973), and Kotler et al. (1973) have all shown an increased risk of sudden death in this group.

Holter continuous electrocardiogram monitoring (Holter, 1957) has been of particular value in the assessment of arrhythmias in ambulatory patients (Bleifer et al., 1974). A standard 12 lead electrocardiogram tracing over 1 minute detects ventricular premature beats in 8 per cent of patients with coronary artery disease, while 12 hours of Holter monitoring in the same group shows ventricular premature beats in 62 per cent of patients (Lown and Wolf, 1971). Thus Holter monitoring is a valuable tool in defining the incidence of ventricular premature beats in a high risk population such as patients after acute myocardial infarction (Lown and Wolf, 1971).

The aims of the present study were to assess the incidence of ventricular arrhythmias in the first year after myocardial infarction and to note any change in pattern during this period. The effect of infarct site and size on the incidence of these arrhythmias was also evaluated.

\section{Subjects and methods}

A prospective study was performed using Holter 24-hour electrocardiogram tape monitoring to assess the incidence of ventricular arrhythmias in the first year after acute myocardial infarction. Patients were initially studied while ambulatory in hospital at approximately 14 days (range 7 to 24 days) after acute infarction (entry study), and had repeat 24-hour Holter monitoring at 3-monthly intervals for 1 year. A clinical examination and standard 12 lead electrocardiogram were performed at each 3-monthly review, with chest radiographs at 3 months, 6 months, and 12 months.

A 24-hour Holter study was performed in a group of normal subjects to assess the incidence of ventricular arrhythmias in the general population.

'Significant' ventricular arrhythmias were defined as ventricular premature beats (VPB) more frequent than 1 in 10 normal beats (VPB $>1$ in 10), ventricular bigeminy or trigeminy, multifocal VPB, salvos ( 2 or 3 consecutive VPB), $R$ on T phenomenon ( $R$ wave interrupting the preceding $T$ wave), and ventricular tachycardia (4 or more consecutive VPB). 'Non-significant' ventricular arrhythmias referred to all other VPB and 'all' ventricular arrhythmias included either 'significant' or 'nonsignificant' ventricular arrhythmias.

The incidence of ventricular arrhythmias was also assessed relative to the site and size of infarction. All anteroseptal and anterolateral infarcts were included in the anterior group and all inferior, inferolateral, and true posterior infarcts were included in the inferior/posterior group.

Patients were arbitrarily divided into two groups on the basis of the maximum height of enzyme rise. Those patients with a peak AST (aspartate aminotransferase) of greater than 200 IU/1 (mean $347 \pm 151 \mathrm{SD})$ were compared with those with a peak AST less than $200 \mathrm{IU} / 1$ (mean $112 \pm 50 \mathrm{SD}$ ). Creatine kinase measurements were not available on a regular basis at the onset of the trial and were not measured. Patients included in the group with cardiac failure in CCU were those who had interstitial or alveolar pulmonary oedema on chest radiograph or those with persistent hypotension, oliguria, and poor peripheral circulation.

\section{PATIENT POPULATION}

Patients were randomly selected from those treated in the coronary care unit of the Alfred Hospital who had definite myocardial infarction diagnosed on the basis of a typical history of chest pain, serial enzyme rises greater than 50 per cent above normal levels, and an evolving electrocardiographic pattern, with loss of $R$ wave amplitude or development of new pathological $Q$ waves.

One hundred and eight patients were initially entered into the trial consisting of 92 men and 16 women, with an average age of $\mathbf{5 4 . 2}$ years (range 37 to 68 years). Fifty-two patients had anterior infarction, 53 had inferior infarction, and 3 had true posterior infarction. Thirty-four patients did not complete the 12 months of follow-up (Table 1). Because of tape malfunction or battery failure 40 of 386 electrocardiogram tapes $(10 \%)$ failed to record and as this was not discovered till a later date these tapes could not be repeated. As a result analysis could be performed on 95 entry tapes, 76 tapes at 3 and 6 months, 72 tapes at 9 months, and 66 tapes at 12 months.

The first 90 patients were considered for a prospective double blind trial to assess the effect of practolol $200 \mathrm{mg}$ twice daily on the incidence of ventricular arrhythmias after infarction (Federman et al., 1976). Many of the patients were unwilling or unsuitable for this study and increasing reports of the side effects of practolol led to premature cessation of the trial. The results showed no significant reduction in the incidence of ventricular

Table 1 Patient withdrawals before 1 year

\begin{tabular}{lr}
\hline Patient unwilling to continue & 18 \\
Patient geographically unsuitable for regular review & 7 \\
Death & 4 \\
Miscellaneous & 5 \\
\hline Total & 34 \\
\hline
\end{tabular}


arrhythmias in patients on practolol though salvos of ventricular premature beats were present for a lower percentage of the hours studied (Federman et al., unpublished). Those patients in the practolol study have been included in this presentstudy. Fortythree patients had practolol on at least one their of 3-monthly reviews. The other cardiac medications taken by patients during the study included digoxin (39 patients), quinidine (7 patients), procainamide (3 patients), and propranolol (2 patients). There was no significant difference in the incidence of ventricular arrhythmias in patients taking these medications and those who were not and, therefore, the results are not presented separately.

A control group of 21 normal subjects from the hospital staff or their relatives was studied with 24-hour Holter monitoring on one occasion while performing their normal activities. These subjects had no past history of cardiac disease and were on no medications at the time of study. They all had a normal 12 lead electrocardiogram apart from one which showed a left anterior hemiblock and one which showed one atrial premature beat. All had normal chest $x$-ray films, were normotensive, and had a normal physical examination. There were 4 women and 17 men, average age 49.9 years (range 40 to 66 years).

\section{DATA RECORDING AND ANALYSIS}

Holter electrocardiogram tape monitoring was successful for an average of 21.9 hours (range 7 to 24 hours) in the post-infarction group and 20.8 hours (range 11 to 24 hours) in the control group. Tapes were analysed using an Avionics Dynamic Electrocardioscanner, initially model 650 and later model 660. A modified lead V5 was used. Tapes were scanned at fast speed, with rate sampling at each hour. All arrhythmias were analysed at normal speed with samples recorded on a strip chart recorder at $25 \mathrm{~mm} / \mathrm{s}$. In cases with a high incidence of arrhyth-

Table 2 Incidence of 'significant' ventricular arrhythmias $(V A)$ averaged over first year after infarction

\begin{tabular}{lll}
\hline Arrhythmia & $\begin{array}{l}\text { \% of patient } \\
\text { studies with } \\
\text { VA }\end{array}$ & $\begin{array}{l}\% \text { hours studied } \\
\text { with VA }\end{array}$ \\
\hline VPB > 1 in 10 normal beats & 45 & 37 \\
Multifocal VPB & 39 & 26 \\
Salvos (2 or 3 VPB) & 26 & 14 \\
Bigeminy/Trigeminy & 14 & 23 \\
R on T phenomenon & 4 & - \\
Ventricular tachycardia & 1 & - \\
$\quad(>4$ VPB) & 54 & 40 \\
\hline Total & 5 &
\end{tabular}

VPB, ventricular premature beats. mias the total tape was played back on to a multichannel recorder at $3.3 \mathrm{~mm} / \mathrm{s}$, with rhythm disturbances being read manually.

In each study the number of hours during which arrhythmias occurred was documented and by relating this to the total number of hours recorded the percentage of studied hours showing arrhythmia was assessed.

Statistical analysis was performed using the $\chi^{2}$ test with Yates correction for continuity and the unpaired Student's t test.

\section{Results}

INCIDENCE OF VENTRICULAR ARRHYTHMIAS IN PATIENTS AFTER MYOCARDIAL

INFARCTION (Table 2, Figs 1 and 2)

The total incidence of 'all' ventricular arrhythmias and the incidence of 'significant' ventricular arrhythmias were high at entry and remained persistently high at each 3-month study during the first year (Fig. 1). 'All' ventricular arrhythmias occurred in 80 per cent of patients averaged over the first year and 'significant' ventricular arrhythmias in 54 per cent of patients. The incidence of these arrhythmias was slightly lower at entry than at subsequent periods of study being 77 per cent for 'all' ventricular arrhythmias and 42 per cent for 'significant' ventricular arrhythmias. This difference was not statistically significant. Seventy-seven patients had 3 or more successful tapes for analysis and of these $61(79 \%)$ showed significant ventricular arrhythmias on at least 1 tape, $3(4 \%)$ showed no

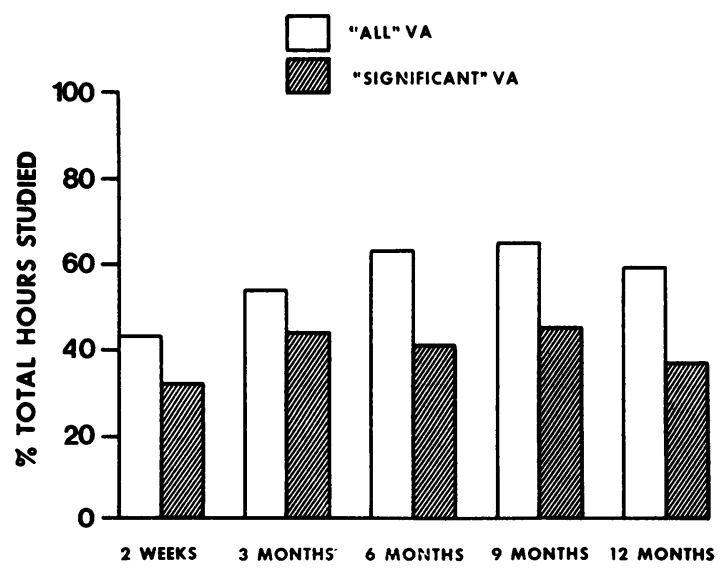

PERIOD FOLLOWING INFARCTION

Fig. 1 Incidence of 'all' and 'significant' ventricular arrhythmias (VA) at each study period in the first year after myocardial infarction. 


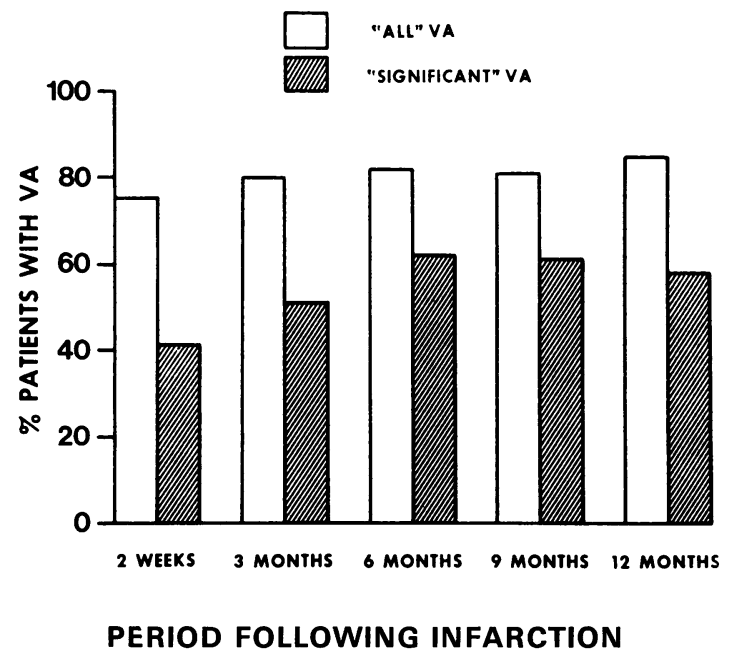

Fig. 2 Percentage of studied hours that showed 'all' and 'significant' ventricular arrhythmias (VA) at each study period in the first year after myocardial infarction.

ventricular arrhythmias on all studies, and $13(17 \%)$ showed only non-significant ventricular arrhythmias.

'All' ventricular arrhythmias occurred for 57 per cent of the hours studied when averaged over the first year and 'significant' ventricular arrhythmias for 40 per cent of the hours studied. At entry the frequency of ventricular arrhythmias was significantly lower than for any of the other study periods being 43 per cent of the studied hours for 'all' ventricular arrhythmias $(P<0.0005)$ and 32 per cent of the studied hours for significant ventricular arrhythmias $(P<0.05)$.

The average incidence of the individual significant arrhythmias was high over the first year as was the percentage of studied hours for which they occurred (Table 2).
INCIDENCE OF VENTRICULAR ARRHYTHMIAS IN CONTROL PATIENTS

Of the 21 control patients, $10(48 \%)$ had 'all' ventricular arrhythmias and $4(19 \%)$ had 'significant' ventricular arrhythmias. These results were significantly lower than the corresponding results of 80 per cent and 54 per cent for the postinfarction patients, with $\mathrm{P}<0.005$ in both cases. 'All' ventricular arrhythmias occurred for 28 per cent of the hours studied in the control group with 'significant' ventricular arrhythmias occurring for 35 per cent of the hours studied. The result for 'all' ventricular arrhythmias was significantly lower than the 57 per cent of hours studied for postinfarction patients $(P<0.025)$; however, the difference did not reach significant levels for 'significant' ventricular arrhythmias.

When the individual 'significant' ventricular arrhythmias were analysed VPB $>1$ in 10 occurred in 3 controls $(14 \%)$ for 39 per cent of the hours studied, multifocal VPB in 2 controls $(10 \%)$ for 24 per cent of the hours studied, and no controls had bigeminy/trigeminy, salvos, $R$ on $T$ phenomenon, or ventricular tachycardia. The incidence of VPB $>1$ in 10 and multifocal VPB were both significantly lower than in the post-infarct group, with $\mathrm{P}<0.025$ in both cases.

\section{INCIDENCE OF VENTRICULAR ARRHYTHMIAS}

RELATED TO INFARCT SITE

(Table 3, Figs 3 and 4)

At entry there was no significant difference in the incidence of ventricular arrhythmias between patients with inferior/posterior infarction compared with anterior infarction. After the entry study, however, the incidence for both 'all' and 'significant' ventricular arrhythmias was significantly higher in patients with inferior/posterior infarction as was the percentage of studied hours for which these arrhythmias occurred (Figs 3 and 4).

When the subsets of 'significant' ventricular

Table 3 Incidence of 'significant' ventricular arrhythmias

\begin{tabular}{|c|c|c|c|c|c|c|}
\hline \multirow[t]{2}{*}{ Arrhythmia } & \multicolumn{2}{|c|}{ Infarct site } & \multicolumn{2}{|l|}{ Infarct size } & \multicolumn{2}{|c|}{ Presence of failure in $\mathrm{CCU}$} \\
\hline & Anterior & $\begin{array}{l}\text { Inferior/ } \\
\text { Posterior }\end{array}$ & $\begin{array}{l}\text { Peak } A S T \\
<200 \\
I U / l\end{array}$ & $\begin{array}{l}\text { Peak AST } \\
>200 \\
I U / l\end{array}$ & Absent & Present \\
\hline $\begin{array}{l}\text { VPB > } 1 \text { in } 10 \\
\text { Multifocal VPB } \\
\text { Salvos } \\
\text { Bigeminy/Trigeminy } \\
R \text { on } T\end{array}$ & $\begin{aligned} 39 \% \\
26 \% \\
19 \% \\
10 \% \\
1 \%\end{aligned}$ & $\begin{array}{l}63 \% \star \star \star \star \\
54 \% \star \star \star \\
35 \% \\
21 \% \\
4 \%\end{array}$ & $\begin{array}{r}39 \% \\
28 \% \\
22 \% \\
13 \% \\
2 \%\end{array}$ & $\begin{array}{l}54 \% \star \star \star \\
50 \% \star \star \star \\
30 \% \\
16 \% \\
5 \%\end{array}$ & $\begin{array}{r}44 \% \\
36 \% \\
23 \% \\
15 \% \\
4 \%\end{array}$ & $\begin{array}{l}56 \% \\
54 \% \star \star \\
38 \% \star \\
14 \% \\
3 \%\end{array}$ \\
\hline $\begin{aligned} P \text { value } \star \star \star & <0.0005 \\
\star \star & <0.005 \\
\star & <0.05\end{aligned}$ & & & & & & \\
\hline
\end{tabular}




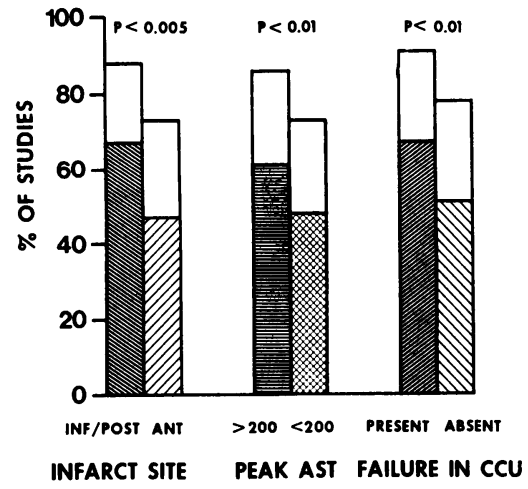

Fig. 3 Incidence of ventricular arrhythmias (VA) averaged for all study periods related to infarct site, peak aspartate aminotransferase level (IU/l) and presence of cardiac failure while patient in the CCU. 'All' VA shown by height of column; 'significant' $V A$ shown by shaded area.

arrhythmias were analysed the higher incidence in inferior/posterior infarct patients after entry remained significant for each group except for $R$ on $T$ where the number of cases with this arrhythmia proved too small for significance to be reached (Table 3 ).

\section{INCIDENCE OF VENTRICULAR ARRHYTHMIAS}

RELATED TO MAXIMUM ENZYME RISE

(Table 3, Figs 3 and 4)

In patients with a maximum AST greater than $200 \mathrm{IU} / 1$ there were 202 tape studies over the

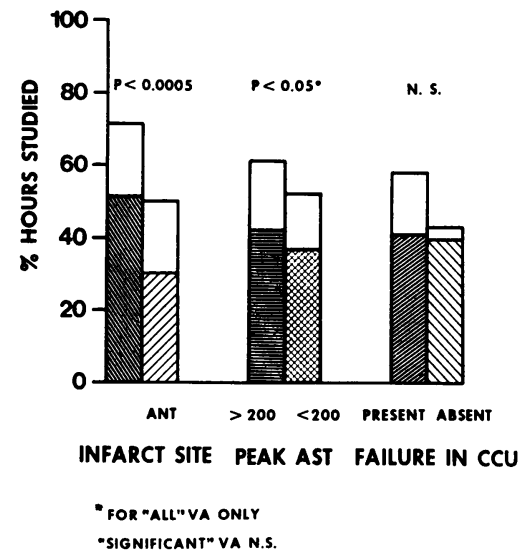

Fig. 4 Percentage of studied hours that showed 'all' and 'significant' ventricular arrhythmias $(V A)$ averaged for all study periods and related to infarct site, peak aspartate aminotransferase level $(I U / l)$, and presence of cardiac failure while patient in CCU. ' $A l l$ ' $V A$ shown by height of column; 'significant' $V A$ shown by shaded area. *For 'all' VA only.
12 months for analysis, compared with 184 tape studies in patients with a maximum AST less than $200 \mathrm{IU} / 1$. Patients in the higher enzyme group proved to have a significantly greater incidence of ventricular arrhythmias over the first year after infarction (Fig. 3).

The percentage of studied hours for which arrhythmias occurred was also higher in patients with a maximum AST greater than $200 \mathrm{IU} / 1$, with this difference proving significant for 'all' ventricular arrhythmias $(P<0.05)$ but not for 'significant' ventricular arrhythmias (Fig. 4).

When the individual subsets of 'significant' ventricular arrhythmias were analysed, patients with an AST greater than 200 had a significantly higher incidence of VPB $>1$ in 10 and multifocal VPB. Though there was a higher incidence of bigeminy/trigeminy, salvos, and $\mathrm{R}$ on $\mathrm{T}$ phenomenon, these results were not statistically significant (Table 3).

INCIDENCE OF VENTRICULAR ARRHYTHMIAS

RELATED TO PRESENCE OF CARDIAC

FAILURE IN CORONARY CARE UNIT

In patients without failure in the CCU 299 studies were available for analysis compared with 87 studies for analysis in patients with cardiac failure in CCU. Patients with failure in CCU proved to have a significantly higher incidence of ventricular arrhythmias during the first year after infarction (Fig. 3). The percentage of studied hours for which arrhythmias occurred did not prove to be statistically different in the two groups.

When the individual significant arrhythmias were analysed there was a significant increase in the incidence of multifocal VPB $(P<0.05)$ and salvos $(P<0.01)$ in the group with failure in the CCU. The incidence of VPB $>1$ in 10 was also higher in this group but did not reach significant levels and there was no increase in bigeminy/trigeminy.

RELATION OF HOLTER MONITORING TO RESTING ELECTROCARDIOGRAM

The results of Holter monitoring were analysed in patients who had a resting electrocardiogram showing no VPB at all periods of monitoring. These patients would normally have been considered to be free of VPB. In this group 231 tapes were analysed and 75 per cent showed 'all' ventricular arrhythmias for an average of 46 per cent of the hours studied and 43 per cent showed 'significant' ventricular arrhythmias for 30 per cent of the hours studied. These results though slightly lower than the overall incidence of ventricular arrhythmias observed in the post-infarction group were not significantly so. When the subsets of 'significant' ventricular 
Table 4 Deaths in first year

\begin{tabular}{|c|c|c|c|}
\hline Patient & Infarct site & Holter monitoring result & Time and mode of death \\
\hline $54 \mathrm{~F}$ & Inferior & $\begin{array}{l}\text { Entry-non-significant VA for } 24 \% \text { hours } \\
\text { studied }\end{array}$ & Died suddenly 2 months after infarct \\
\hline $61 M$ & Inferior & $\begin{array}{l}\text { Entry-salvos in } 1 \text { hour; } \\
3 \text { months tape-no VA }\end{array}$ & Died suddenly 5 days after 3 -month review \\
\hline $60 \mathrm{M}$ & Anterior & $\begin{array}{l}\text { Entry-non-significant VA for } 21 \% \text { hours } \\
\text { studied }\end{array}$ & $\begin{array}{l}\text { Inferior infarct } 11 \text { weeks after discharge; died } \\
\text { after several cardiac arrests on } 17 \text { th day }\end{array}$ \\
\hline $52 M$ & Anterior & $\begin{array}{l}\text { Entry-'non-significant' VA for } 13 \% \text { hours } \\
\text { studied; } \\
3 \text { months tape-'non-significant' VA for } \\
48 \% \text { hours studied; } \\
6 \text { months tape-'all' VA for } 95 \% \text { hours studied, } \\
\text { 'significant' VA for } 86 \% \text { hours studied }\end{array}$ & $\begin{array}{l}\text { Died suddenly after chest pain } 1 \text { week after } \\
6 \text {-month review }\end{array}$ \\
\hline
\end{tabular}

VA, ventricular arrhythmia.

arrhythmias were analysed 31 per cent of studies showed VPB $>1$ in 10, 30 per cent showed multifocal VPB, 13 per cent showed bigeminy/trigeminy, 16 per cent showed salvos, 5 per cent showed $R$ on $T$, and ventricular tachycardia was not observed.

In patients with 1 or more VPB on a resting electrocardiogram the corresponding Holter 24-hour tape monitor showed significant ventricular arrhythmias in 100 per cent of cases.

\section{DEATHS (Table 4)}

Four deaths occurred during the study period. All patients had ventricular arrhythmias on at least 1 occasion, and in the 3 patients dying suddenly 2 had shown 'significant' ventricular arrhythmias.

\section{Discussion}

The incidence of VPB is high at 2 weeks after myocardial infarction and remains persistently high during the first year. There is a tendency for VPB to become more frequent after the entry study at 2 weeks but this only became significant for the percentage of studied hours for which 'all' and 'significant' ventricular arrhythmias occurred ( $P$ values of $<0.0005$ and $<0.05$, respectively). A possible explanation is that the level of physical activity increases once patients leave hospital, and Jelinek and Lown (1974) have shown that the incidence of VPB may double during exercise with major repetitive VPB increasing by a factor approaching 8 .

The total incidence of VPB in our series was 80 per cent which is similar to the incidence observed in other studies on patients with coronary artery disease. Lown et al. (1975) using 24-hour Holter monitoring found VPB to be present in 85 per cent of ambulatory patients, Moss et al. (1971) using 6-hour Holter monitoring found an incidence of
VPB of 72 per cent at 3 weeks after infarction, and Kotler et al. (1973) found an incidence of 80 per cent using 12-hour Holter monitoring. The incidence of 'significant' ventricular arrhythmias was 54 per cent which is similar to the incidence of 41 per cent for 'advanced grade or repetitive forms' of VPB described by Lown et al. (1975) and the incidence of 42 per cent for 'serious' VPB described by Vismara et al. (1975b) in patients convalescing in hospital from acute myocardial infarction. The incidence of salvos ( 2 or 3 VPB) in our study was 26 per cent and ventricular tachycardia ( $>3 \mathrm{VPB}$ ) was 1 per cent. Our incidence of ventricular tachycardia was lower than the 2.5 per cent observed by Kotler et al. (1973), the 4 per cent by Moss et al. (1971), and the 6 per cent by Vismara et al. (1975b), since in these studies ventricular tachycardia was defined as greater than 2 consecutive VPB.

Our control group, though small, had a lower incidence of 'all' and 'significant' ventricular arrhythmias $(P<0.005)$, with 'all' but not 'significant' ventricular arrhythmias occurring for a lower percentage of the hours studied $(P<0.025)$. Our incidence in this group of normal subjects was higher than the incidence described by Raftery and Cashman (1976) who used 24-hour Holter monitoring and found VPB in only 9 of $53(17 \%)$ subjects who had previously been screened to exclude heart disease. Clarke et al. (1976), again in a screened population, found a higher incidence with 63 of 86 normal subjects $(73 \%)$ having VPB. However only 10 of these (12\%) showed VPB of 'serious prognostic significance'. Hinkle et al. (1969) studied a random group of 301 active men of median age 55 years who had not been screened. He found VPB in 62.2 per cent of subjects; however, there was a significant association between the presence of VPB and the presence of coronary heart disease at the time of examination. Patients with VPB had an increased risk of subsequent death from coron- 
ary heart disease. Thus, it appears that in patients with coronary artery disease the incidence of ventricular arrhythmias is higher than in the general population and that this may be the factor producing sudden death when the threshold to ventricular fibrillation is reduced during periods of ischaemia. All patients in our study who died suddenly had VPB on at least one of their studies and 2 of the 3 had shown 'significant' ventricular arrhythmias.

The Coronary Drug Project Research Group (1973) and the study by Chiang et al. (1969) have both shown an increased incidence of sudden death in patients with VPB present on a standard electrocardiogram. Our results and the results of others have shown a poor correlation between the incidence of VPB on a standard electrocardiogram and the incidence using Holter monitoring (Lown et al., 1975). In patients with no VPB on their 12 lead electrocardiogram, 24-hour tape analysis showed that 75 per cent had 'all' ventricular arrhythmias and 43 per cent 'significant' ventricular arrhythmias. In those patients who had VPB on a 12 lead electrocardiogram the corresponding 24-hour Holter monitoring showed 'significant' ventricular arrhythmias in all cases. The 12 lead electrocardiogram is thus an insensitive method of assessing the presence of potentially serious arrhythmias; however, the presence of only 1 VPB on a standard electrocardiogram is likely to be associated with 'significant' ventricular arrhythmias on Holter monitoring.

During the convalescent period from infarction there is no difference in the incidence of ventricular arrhythmias for patients with inferior or true posterior infarction compared with anterior infarction. In the subsequent year, however, there is a significantly higher incidence of ventricular arrhythmias in patients with inferior/posterior infarction $(P<0.005)$, with these arrhythmias occurring for a greater percentage of the studied hours $(P<0.0005)$. Hinkle et al. (1969), Moss et al. (1971), Lown et al. (1975), and Vismara et al. (1975a, b) did not comment on the incidence of ventricular arrhythmias related to infarct site. However, Biddle et al. (1976) using 6-hour Holter monitoring have noted a higher incidence of 'serious ventricular arrhythmias' in patients with 'diaphragmatic' infarcts in the first 6 months after hospital discharge. The explanation for this finding is not clear though it may be related to the ability of patients with inferior infarction to return to a greater level of physical activity because of less left ventricular dysfunction.

In patients with evidence of more extensive myocardial damage as judged by a peak serum AST greater than $200 \mathrm{IU} / 1$ or with definite cardiac failure in CCU we found a greater incidence of ventricular arrhythmias during the first year after infarction $(\mathrm{P}<0.05)$. Biddle et al. (1976) noted that patients who had serious ventricular arrhythmias in the acute phase of infarction had significantly greater degrees of myocardial dysfunction as judged by pulmonary artery and pulmonary wedge pressures. In contrast to our results, however, they found no association between the long-term incidence of serious ventricular arrhythmias and the haemodynamic findings at the time of acute infarction.

The number of deaths during the first year of our trial have been small and no pattern of arrhythmias can be implicated as indicating a higher risk of sudden death since 79 per cent of patients who had 3 or more tapes showed significant ventricular arrhythmias on at least one occasion. There is obviously a need for long-term review and patients in the current series continue to be assessed 6-monthly and to have 24-hour Holter monitoring on a yearly basis. It is hoped that some pattern may be defined which will isolate those patients at increased risk. The recently reported Multicentre International Study (1975) and the study by Wilhelmsson et al. (1974) make a strong case for the use of long-term beta-adrenergic blocking agents to prevent sudden death; however, our experience with practolol showed no significant reduction in ventricular arrhythmias apart from a reduction in the percentage of studied hours for which salvos occurred (Federman et al., 1976).

\section{Conclusion}

The incidence of ventricular arrhythmias is persistently high in the first year after myocardial infarction and is significantly higher than the incidence in normal control subjects. Patients with inferior/posterior infarction or those with evidence or more extensive myocardial damage have a higher incidence of ventricular arrhythmias in the long term.

\section{References}

Biddle, T. L., Yu, P. N., Akiyama, T., Hodges, M., Kronenberg, M. W., and Roberts, D. L. (1976). Ventricular arrhythmias and cardiac hemodynamics in patients with myocardial infarction. Comparison of acute and posthospitalization phases. Electrocardiology, 9, 297-302.

Bleifer, S. B., Bleifer, D. J., Hansmann, D. R., Sheppard, J. J., and Karpman, H. L. (1974). Diagnosis of occult arrhythmias by Holter electrocardiography. Progress in Cardiovascular Diseases, 16, 569-599.

Chiang, B. N., Perlman, L. V., Ostrander, L. D., Jr., and Epstein, F. H. (1969). Relationship of premature systoles to coronary heart disease and sudden death in the Tecumseh epidemiologic study. Annals of Internal Medicine, 70, 1159-1166. 
Clarke, J. M., Shelton, J. R., Venning, G. R. Hamer, J., and Taylor, S. (1976). The rhythm of the normal human heart. Lancet, 2, 508-512.

Coronary Drug Project Research Group (1973). Prognostic importance of premature beats following myocardial infarction. Experience in the Coronary Drug Project. Fournal of the American Medical Association, 223, 1116-1124.

Federman, J., Whitford, J. A., Anderson, S. T., and Pitt, A. (1976). Effect of practolol on ventricular tachyarrhythmias after myocardial infarction (abstract). Australian and New Zealand Fournal of Medicine, 6, 182-183.

Hinkle, L. E., Jr., Carver, S. T., and Stevens, M. (1969). The frequency of asymptomatic disturbances of cardiac rhythm and conduction in middle-aged men. American fournal of Cardiology, 24, 629-650.

Holter, N. J. (1957). Radioelectrocardiography: a new technique for cardiovascular studies. Annals of the New York Academy of Sciences, 65, 913-923.

Jelinek, M. V., and Lown, B. (1974). Exercise stress testing for exposure of cardiac arrhythmias. Progress in Cardiovascular Diseases, 16, 497-522.

Kotler, M. N., Tabatznik, B., Mower, M. M., and Tominaga, S. (1973). Prognostic significance of ventricular ectopic beats with respect to sudden death in the late postinfarction period. Circulation, 47, 959-966.

Kuller, L. (1966). Sudden and unexpected non-traumatic deaths in adults: a review of epidemiological and clinical studies. Fournal of Chronic Diseases, 19, 1165-1192.

Lown, B., Calvert, A. F., Armington, R., and Ryan, M. (1975). Monitoring for serious arrhythmias and high risk of sudden death. Circulation, 51 and 52, Suppl. III, 189-198.

Lown, B., and Wolf, M. (1971). Approaches to sudden death from coronary heart disease. Circulation, 44, 130-142.

Moss, A. J., Schnitzler, R., Green, R., and Decamilla, J. (1971). Ventricular arrhythmias 3 weeks after acute myo- cardial infarction. Annals of Internal Medicine, 75, 837-841. Multicentre International Study (1975). Improvement in prognosis of myocardial infarction by long-term betaadrenoreceptor blockade using practolol. British Medical fournal, 3, 735-740.

Raftery, E. B., and Cashman, P. M. M. (1976). Long-term recording of the electrocardiogram in a normal population. Postgraduate Medical fournal, 52, Suppl. 7, 32-37.

Schaffer, W. A., and Cobb, L. A. (1975). Recurrent ventricular fibrillation and modes of death in survivors of out-ofhospital ventricular fibrillation. New England fournal of Medicine, 293, 259-262.

Schwartz, C. J., and Walsh, W. J. (1971). The pathologic basis of sudden death. Progress in Cardiovascular Diseases, $13,465-481$.

Vismara, L. A., Amsterdam, E. A., and Mason, D. T. (1975a). Relation of ventricular arrhythmias in the late hospital phase of acute myocardial infarction to sudden death after hospital discharge. American fournal of Medicine, 59, 6-12.

Vismara, L. A., DeMaria, A. N., Hughes, J. L., Mason, D. T., and Amsterdam, E. A. (1975b). Evaluation of arrhythmias in the late hospital phase of acute myocardial infarction compared to coronary care unit ectopy. British Heart fournal, 37, 598-603.

Wilhelmsson, C., Vedin, J. A., Wilhelmssen, L., Tibblin, G., and Werkö, L. (1974). Reduction of sudden deaths after myocardial infarction by treatment with alprenolol. Lancet, 2, $1157-1160$.

Requests for reprints to Dr A. Pitt, Cardiovascular Diagnostic Service, Alfred Hospital, Commercial Road, Prahran 3181, Victoria, Australia. 